\title{
Iridium oxide as actuator material for the ISFET-based sensor-actuator system
}

\author{
W. Olthuis, J. G. Bomer and P. Bergveld \\ Department of Electrical Engineering, University of Twente, P.O. Box 217, 7500 AE Enschede (The Netherlands) \\ M. Bos and W. E. van der Linden \\ Department of Chemical Technology, University of Twente, P.O. Box 217, 7500 AE Enschede (The Netherlands)
}

\begin{abstract}
Acid or base concentrations can be determined by performing an acid-base titration with Coulometrically generated $\mathrm{OH}^{-}$or $\mathrm{H}^{+}$ions at a noble-metal actuator electrode in close proximity to the pH-sensitive gate of an ISFET. The ISFET is used as the indicator electrode to detect the equivalence point in the titration curve. The potential of the actuator electrode during the generation of the titrant is relatively high for the anodic water electrolysis (or relatively low for the cathodic reaction). Consequently other redox couples which are possibly present in the sample solution can interfere with the water electrolysis. This reduces the efficiency of the current to titrant generation on which this measurement relies. To overcome this problem, iridium oxide has been used as a new electroactive material for the actuator electrode. The reversible redox reaction in this metal oxide occurs at a favourable potential and is attended by the exclusive uptake or release of protons, making a titration possible. It is shown that a Coulometric titration in the presence of $\mathrm{Cl}^{-}$ions, formerly not possible with the noble-metal actuator electrode because of the redox interference, can now successfully be carried out with iridium oxide as the actuator material. Calculations show that the ISFET pH-sensor is well suited to determining accurately the equivalence point in the steep part of the titration curve; because of its short response time.
\end{abstract}

\section{Introduction}

Coulometric generation of $\mathrm{H}^{+}$or $\mathrm{OH}^{-}$ ions by the electrolysis of water at a noblemetal actuator electrode permits the control of the $\mathrm{pH}$ at the surface of that electrode. The ions thus generated are used as a titrant to perform an acid-base titration in a small volume formed by the area of the actuator electrode, typically $1 \mathrm{~mm}^{2}$, and the thickness of the diffusion layer. Hence, the measurement is carried out in a volume of a few microlitres, whereas the remainder of the sample solution is unaffected. By placing a pH-sensitive ISFET in close proximity to the actuator electrode, one can measure the local concentration change of $\mathrm{H}^{+}$or $\mathrm{OH}^{-}$ions. The rate of this change is related to the bulk concentrations of the buffering components in the solution [1].

Figure 1(a) shows a typical registration of a Coulometric titration carried out in an alkaline solution with the set-up as described in the Experimental Section using a Pt actuator/ISFET sensor device. The equivalence time $t_{\text {eq }}$, that is the time needed to reach the equivalence point in the titration curve, depends on the base concentration of the bulk. A model has been presented [2] describing the relation between $t_{\mathrm{eq}}$ and this bulk concentration.

The potential of the Pt actuator electrode, $V_{\mathrm{Pt}}$, reaches a value of $1.5 \mathrm{~V}$ versus a saturated calomel electrode (SCE) during the titration. All potentials in this paper are relative to an SCE. A redox couple with a standard potential $<1.5 \mathrm{~V}$, present in the solution, might interfere with the anodic water electrolysis at the actuator electrode. Such reactions affect the actual measurement of the equivalence time: a longer time will be needed to reach the equivalence point in the titration curve, because the electron to proton efficiency of the anodic electrolysis of water 


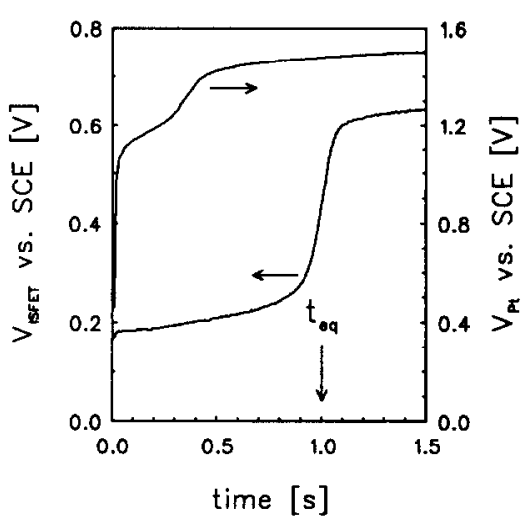

(a)

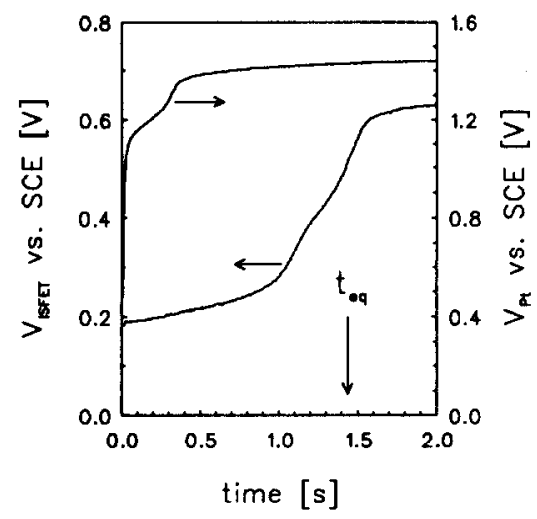

(b)

Fig. 1. Result of a Coulometric titration with a Pt actuator/ISFET sensor device: (a) in $2 \mathrm{mM} \mathrm{KOH}$, $t_{\text {eq }}=1.01 \mathrm{~s}$; (b) in $2 \mathrm{mM} \mathrm{KOH}+50 \mathrm{mM} \mathrm{KCl}, t_{\text {eq }}=$ $1.46 \mathrm{~s}$. $V_{\text {ISFET }}$ is the ISFET amplifier output signal and $V_{\mathrm{Pt}}$ the $\mathrm{Pt}$ electrode potential. The actuator current density was $20 \mu \mathrm{A} / \mathrm{mm}^{2}$.

decreases if this redox reaction occurs first. This situation is shown in Fig. $1(\mathrm{~b}) . \mathrm{Cl}^{-}$ions were added to the solution in which the experiment of Fig. 1(a) was carried out and the experiment was repeated. The reaction

$2 \mathrm{Cl}^{-} \rightarrow \mathrm{Cl}_{2}+2 e$

affects the titration curve, resulting in a higher value for the equivalence time $t_{\mathrm{eq}}$ as compared with the experiment of Fig. 1(a). In order to restrict the effect of $\mathrm{Cl}^{-}$and other interfering redox couples, electroactive materials have been studied that can exchange $\mathrm{H}^{+}$or $\mathrm{OH}^{-}$ ions at a lower potential than that where the oxidation of $\mathrm{Cl}^{-}$to $\mathrm{Cl}_{2}$ occurs (but higher than the potential of cathodic water electrolysis). Furthermore, the exchange of ions must be reversible, exclusive and fast as compared with the time to reach the equivalence point. In this respect, the electrochemical properties of iridium oxide have been studied and a device was fabricated of which the iridium oxide film was electrochemically grown.

Recently, the results of an all-iridium oxide device have been presented [3]. In this paper the results of a sensor-actuator device of which only the actuator electrode consists of iridium oxide are presented; the ISFET is used as a fast sensor for the indication of the equivalence point. The difference in performance is summarized at the end of this paper.

\section{Experimental}

Preparation of the iridium oxide actuator/ISFET sensor system

As illustrated in Fig. 2, an iridium film of approximately $100 \mathrm{~nm}$ thickness was evaporated on top of a 2 inch $\mathrm{Si}$ wafer with $\mathrm{SiO}_{2}$ ISFETs fabricated following the usual n-MOS processing steps [4]. Patterning of this film was accomplished by using a positive photoresist lift-off mask. A layer of polyimide was spun on the wafer in which holes were etched both to contact the ISFET and the actuator electrode, and to free the area of the actuator electrode to be exposed to the solution. After dicing the wafer, the chips were glued on a $1 \mathrm{~cm} \times 5 \mathrm{~cm}$ piece of printed circuit board and connected to the available copper strips with bonding wires. The copper strips, the bonding wires and the edges of the chip were covered with epoxy for insulation and protection. The iridium actuator electrode was subsequently oxidized in a $0.5 \mathrm{M}$ $\mathrm{H}_{2} \mathrm{SO}_{4}$ solution by applying either a triangular potential sweep [5] or a timecontrolled current pulse to the electrode, which results in an anodic iridium oxide film (AIROF).

\section{Measurement set-up}

All measurements with the AIROF actuator/ISFET sensor device have been carried out with the set-up shown in Fig. 3. 


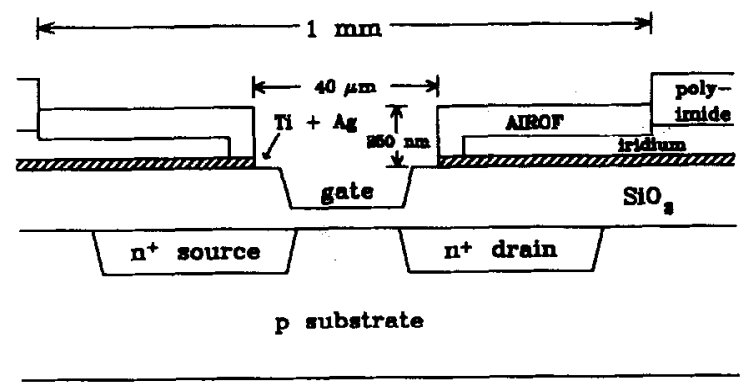

(a)

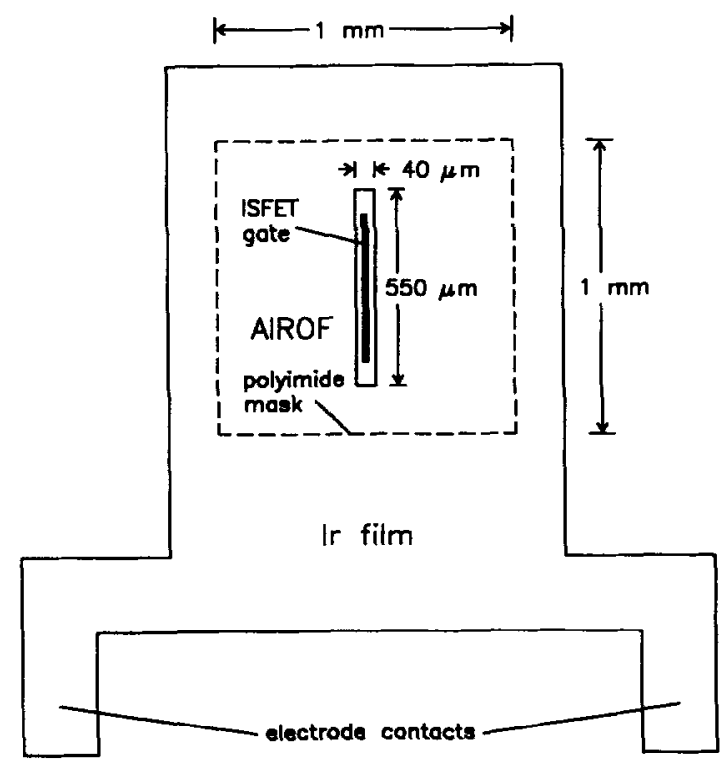

(b)

Fig. 2. (a) Cross section and (b) top view of the AIROF actuator/ISFET sensor device.

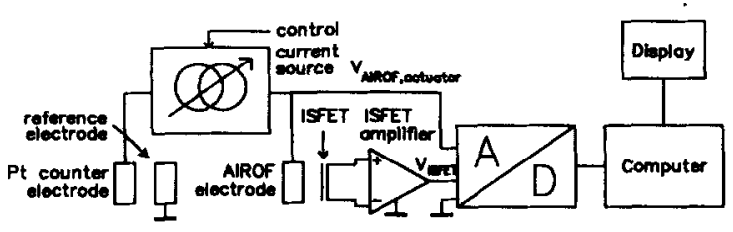

Fig. 3. Measurcment set-up.

The ISFET amplifier keeps both the drain current and the drain-source voltage constant at $100 \mu \mathrm{A}$ and $0.5 \mathrm{~V}$, respectively. Apart from the ISFET amplifier output potential $V_{\text {ISFET }}$, the potential of the iridium oxide actuator electrode, $V_{\text {AIRoF, }}$ was monitored during the titration in order to check whether the electrode potential stayed within the range determined by cathodic and

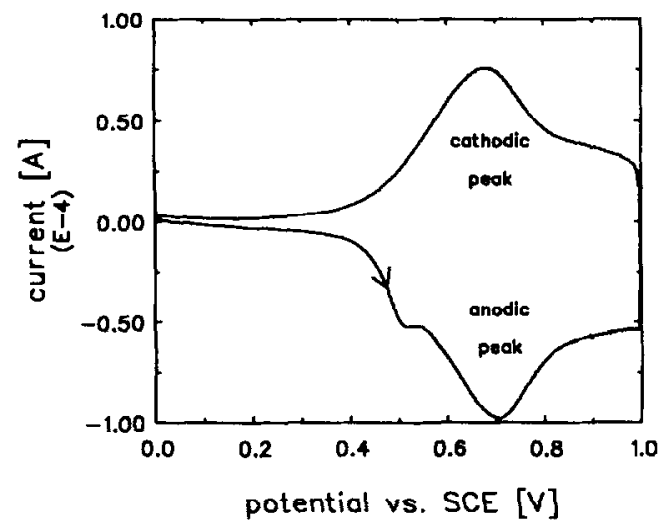

Fig. 4. Cyclic voltammogram of a $1.5 \mathrm{~mm}^{2}$ AIROF, recorded in $0.5 \mathrm{M} \mathrm{H}_{2} \mathrm{SO}_{4}$ for a scan rate of $100 \mathrm{mV} / \mathrm{s}$.

anodic water electrolysis. All Coulometric titrations were carried out with an actuator electrode current density of $20 \mu \mathrm{A} / \mathrm{mm}^{2}$ in a $0.1 \mathrm{M} \mathrm{KNO}_{3}$ supporting electrolyte at room temperature.

\section{Results and discussion}

\section{Characterization}

Figure 4 shows the result of a cyclic voltammogram of an AIROF, recorded in $0.5 \mathrm{M} \mathrm{H}_{2} \mathrm{SO}_{4}$. The anodic and the cathodic peaks are accompanied by the release and uptake of protons, respectively, according to the reaction [5]

$$
\mathrm{IrOOH} \rightleftharpoons \mathrm{IrO}_{2}+\mathrm{H}^{+}+e
$$

The potential at which these peaks are located, $0.7 \mathrm{~V}$, is well within the potentials at which cathodic and anodic water electrolysis occurs at a Pt electrode. The quantity of protons that is exchanged can be estimated from the area of the cyclic voltammogram and for this electrode equals $\approx 15 \mathrm{mC} / \mathrm{cm}^{2}$.

\section{Base-to-acid titrations with the AIROF} actuator/ISFET sensor device

The result of a typical base-to-acid titration carried out in $1 \mathrm{mM} \mathrm{KOH}$ is presented in Fig. 5. This titration was started $1 \mathrm{~min}$ after the AIROF was totally charged with protons 


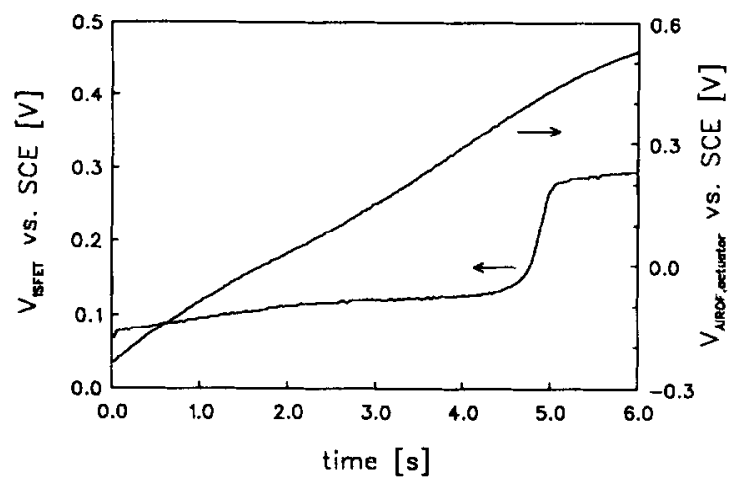

Fig. 5. Result of a typical base-to-acid titration in $1 \mathrm{mM} \mathrm{KOH}, t_{\mathrm{eq}}=4.90 \mathrm{~s}$.

by reducing the film with a cathodic current of $10 \mu \mathrm{A} / \mathrm{mm}^{2}$ for $\approx 15 \mathrm{~s}$. At that moment the electrode potential reached the value that corresponded with the totally reduced state, approximately $-0.25 \mathrm{~V}$ in this solution.

The potential $V_{\text {ISFET }}$, giving the $\mathrm{pH}$ titration curve, changes from approximately 0.075 to $0.30 \mathrm{~V}$. The $\mathrm{pH}$-sensitive gate oxide of the ISFET used in this experiment is $\mathrm{SiO}_{2}$ with a sensitivity of approximately $-32 \mathrm{mV} / \mathrm{pH}$, so that the $\Delta \mathrm{pH}$ measured in Fig. 5 is approximately 8. Note that in many applications (static measurements), $\mathrm{Ta}_{2} \mathrm{O}_{5}-$ or $\mathrm{Al}_{2} \mathrm{O}_{3}$ ISFETs are preferred to $\mathrm{SiO}_{2}$-ISFETs in view of their known drift problems and relatively low $\mathrm{pH}$ sensitivity. However, for this application, the ISFET is used in a dynamic mode of measurement. Only the large signal response time to a $\mathrm{pH}$ step is of importance; this is known to be very fast, of the order of milliseconds [6]. The AIROF actuator potential, $V_{\text {AIROF }}$, at which $t_{\text {eq }}$ is reached is important. In this example, a successful Coulometric titration was accomplished at $0.41 \mathrm{~V}$, which is more than $1 \mathrm{~V}$ lower than the potential $V_{\mathrm{Pr}}$ at which a titration was accomplished with the $\mathrm{Pt}$ actuator electrode as shown in Fig. 1. This result offers favourable prospects for avoiding $\mathrm{Cl}^{-}$ion interference, which occurs at an electrode potential of around 1.4 V. To investigate this further, the experiment just described was repeated after adding $\mathrm{KCl}$ to the sample up to a concentration of $50 \mathrm{mM}$. The time $t_{\mathrm{eq}}$ was found to be $4.95 \mathrm{~s}$, which is within the experimental error of the result of the previous experiment: $4.90 \mathrm{~s}$. The time $t_{\text {eq }}$ for the AIROF/ISFET device is much longer than that of the Pt/ISFET device in comparable base concentrations, as can be concluded from comparing Fig. 5 with Fig. 1. This is probably caused by the formation of a complex in the oxide film, in which the proton that is generated during the redox reaction takes part before it is released in the further course of the oxidation, causing the extra delay time.

\section{Determination of $\mathrm{KOH}$ concentration}

Coulometric titrations were carried out for nine different $\mathrm{KOH}$ concentrations. At each concentration, the measurement was carried out twice; for all nine concentrations, the result of the second measurement corresponded within $1 \%$ to that of the first measurement, indicating a good reproducibility. The result is presented in Fig. 6 .

Based on the modelling of the free diffusion occurring, a linear relation between the square root of $t_{\mathrm{eq}}$ and the base concentration is expected [2]. The measurement is in good agreement with the theory. The slope of the measured curve is $0.27 \mathrm{~s}^{1 / 2} / \mathrm{mM}$, which should be compared to the predicted value [2] of $0.31 \mathrm{~s}^{1 / 2} / \mathrm{mM}$.

\section{Acid-to-base titrations with the AIROF} actuator/ISFET sensor device

The result of a typical acid-to-base titration carried out in $1 \mathrm{mM} \mathrm{HNO} 3$ is presented

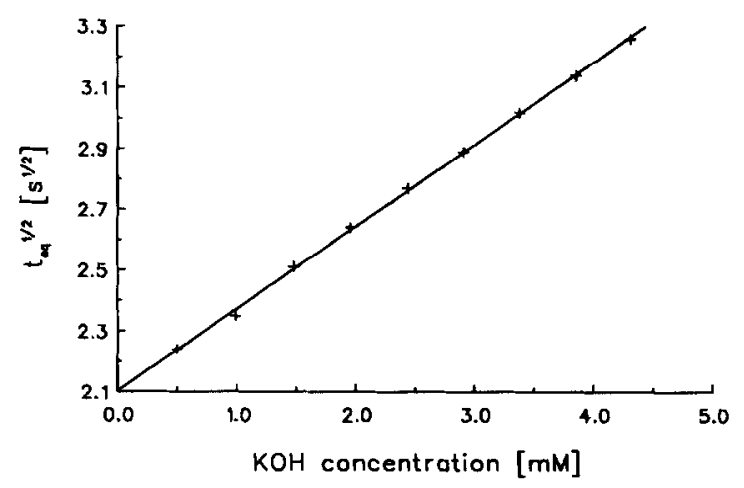

Fig. 6. Square root of $t_{\mathrm{eq}}$ as a function of the $\mathrm{KOH}$ bulk concentration. 


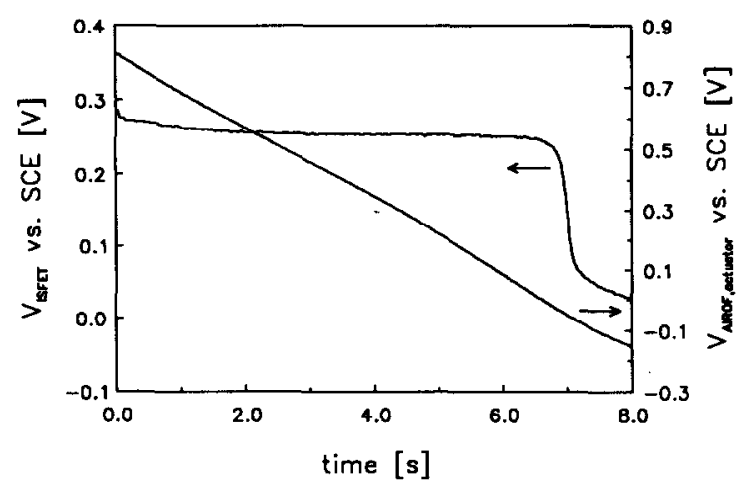

Fig. 7. Result of a typical acid-to-base titration in $1 \mathrm{mM} \mathrm{HNO}_{3}, t_{\mathrm{eq}}=6.98 \mathrm{~s}$.

in Fig. 7. The titration was started 1 min after the AIROF was oxidized by applying an anodic current of $10 \mu \mathrm{A} / \mathrm{mm}^{2}$ for some seconds until the electrode potential reached the value that corresponds with the totally oxidized state, i.e., the state at which the maximum available number of protons is released. The potential in this solution was then equal to approximately 0.7 to $0.8 \mathrm{~V}$.

The $\mathrm{SiO}_{2}$-ISFET potential $V_{\text {ISFET }}$ sharply drops at $t_{\text {eq }}$ from $\approx 0.27$ to $0.03 \mathrm{~V}$, representing a $\triangle \mathrm{pH}$ of about 8 . The AIROF actuator electrode potential at $t_{\text {eq }}$ was $-0.1 \mathrm{~V}$ instead of $-0.9 \mathrm{~V}$ for the potential of a Pt actuator electrode.

\section{Determination of $\mathrm{HAc}$ and $\mathrm{HNO}_{3}$ concentrations}

Measurements for nine different $\mathrm{HNO}_{3}$ and ten different $\mathrm{HAc}$ concentrations were carried out, all with a very good reproducibility: in all cases the result of the second measurement carried out in the same concentration corresponded within $1 \%$ to the result of the first measurement. The result of this series of measurements is presented in Fig. 8.

The measurement results are in good agreement with the expected linear relation between the square root of $t_{\mathrm{eq}}$ and the acid concentration for both $\mathrm{HNO}_{3}$ and HAc. However, the measured slope of the curve representing HAc $\left(0.123 \mathrm{~s}^{1 / 2} / \mathrm{mM}\right)$ is smaller than the model predicts, being $0.149 \mathrm{~s}^{1 / 2} / \mathrm{mM}$. For the curve that represents $\mathrm{HNO}_{3}$ this difference is even larger: the measured slope

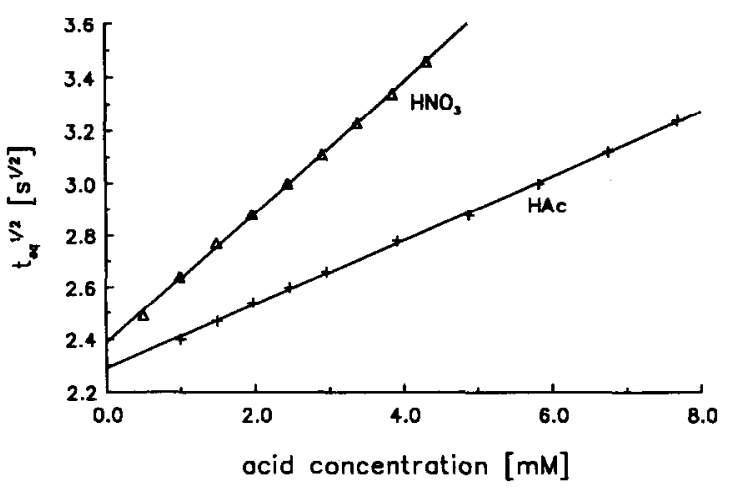

Fig. 8. Square root of $t_{\text {eq }}$ as a function of the $\mathrm{HNO}_{3}$ and HAc bulk concentration.

is $0.250 \mathrm{~s}^{1 / 2} / \mathrm{mM}$, whereas $0.413 \mathrm{~s}^{1 / 2} / \mathrm{mM}$ is expected. The difference can possibly be ascribed to the decreased mobility of the diffusing species: for the calculated slope, the value of the diffusion coefficient valid for aqueous solutions is used, whereas the possibly smaller mobility that occurs in the iridium oxide would decrease the calculated slope.

\section{All-iridium oxide versus iridium oxide actuator/ISFET sensor device}

The major difference between the device discussed in this paper and the recently presented all-iridium oxide sensor-actuator system [3] lies in the response time of the sensor. The response time of the ISFET $\mathrm{pH}$-sensor is theoretically of the order of milliseconds [6], and the measured response time is less than $20 \mathrm{~ms}$ [7]. However, the measured response time of an iridium oxide $\mathrm{pH}$-sensor is optimally $\approx 50 \mathrm{~ms}[7]$.

In order to check whether this difference in response time of the two $\mathrm{pH}$-sensors is relevant to our application, the speed of the base-to-acid transition at the equivalence point is estimated [2]:

$\frac{\partial C_{\mathrm{OH}}}{\partial t}=-j / F\left(\pi D_{\mathrm{OH}} t_{\mathrm{eq}}\right)^{1 / 2}$

where $C_{\mathrm{OH}}$ is the alkaline concentration at the actuator electrode surface, being depleted during the titration. $F$ is Faraday's constant, $j$ is the actuator current density and $D_{\mathrm{OH}}$ the diffusion coefficient of the $\mathrm{OH}^{-}$ ions $\left(D_{\mathrm{OH}}=5.21 \times 10^{-9} \mathrm{~m}^{2} / \mathrm{s}\right.$ at $\left.25^{\circ} \mathrm{C}\right)$. By 
substituting the values given for Fig. 1(a), eqn. (1) yields $\partial C_{\mathrm{OH}} / \partial t=-1.5 \mathrm{mM} / \mathrm{s}$. According to this estimation, the change in $\mathrm{pH}$ from, e.g., 9 to 4 takes about $7 \mathrm{~ms}$. Thus the response time of the sensor determines the accuracy of the sensor-actuator device. The iridium oxide $\mathrm{pH}$ sensor causes a systematic error in $t_{\mathrm{eq}}$ of approximately $(50 \mathrm{~ms} / 1.01 \mathrm{~s})$ $5 \%$ for the values given in Fig. 1(a), whereas the ISFET causes an error of $<2 \%$ under the same circumstances.

Therefore, the equivalence point in the titration curve can be detected with higher accuracy when an ISFET is used as the sensor part of the device. However, the preparation of an all-iridium oxide device is easier than that of the iridium oxide actuator/ ISFET sensor device.

\section{Conclusions}

Coulometric acid-base titrations can successfully be accomplished with an electrochemically grown iridium oxide actuator electrode and an ISFET sensor. Even in the presence of $\mathrm{Cl}^{-}$ions, a base-to-acid titration can successfully be performed with this device, in contrast to titrations carried out with a $\mathrm{Pt}$ actuator/ISFET sensor device, where the $\mathrm{Cl}^{-}$ions interfere with the anodic water electrolysis.

The short response time of the ISFET $\mathrm{pH}$ sensor results in an accurately detected equivalence point in the titration curve.

\section{Acknowledgements}

This investigation is part of the research program of the Foundation for Fundamental Research on Matter (FOM), which is supported by the Netherlands Technology Foundation (STW).

\section{References}

1 W. Olthuis, B. H. van der Schoot, F. Chavez and P. Bergveld, A dipstick sensor for coulometric acid/ base titrations, Sensors and Actuators, 17 (1989) 279-283.

2 W. Olthuis, J. Luo, B. H. van der Schoot, P. Bergveld, M. Bos and W. E. van der Linden, Modelling of non-steady-state concentration profiles at ISFET-based coulometric sensor-actuator systems, Anal. Chim. Acta, 229 (1990) 71-81.

3 W. Olthuis, J. C. van Kerkhof, P. Bergueld, M. Bos and W. E. van der Linden, Preparation of iridium oxide and its application in sensor-actuator systems, Sensors and Actuators B, 4 (1991) 151-156.

4 P. Bergveld and A. Sibbald, Analytical and biomedical applications of ion-selective transistors, in G. Svehla (ed.) Comprehensive Analytical Chemistry, Vol. XXIII, Elsevier, Amsterdam, 1988.

5 S. Gottesfeld and J.D.E. McIntyre, Electrochromism in anodic iridium oxide films II, J. Electrochem. Soc., 126 (1979) 742- 750.

6 L. J. Bousse, P. Bergveld and W. E. van der Linden, Proc. Scientific Sessions on Electrochemical Detection in Flow Analysis, Matrafüred, Hungary, Oct. 1982, p. 257.

7 W. Olthuis, M. A. M. Robben, P. Bergueld, M. Bos and W. E. van der Linden, $\mathrm{pH}$ sensor properties of electrochemically grown iridium oxide, Sensors and Actuators B, 4 (1991) 247-256. 